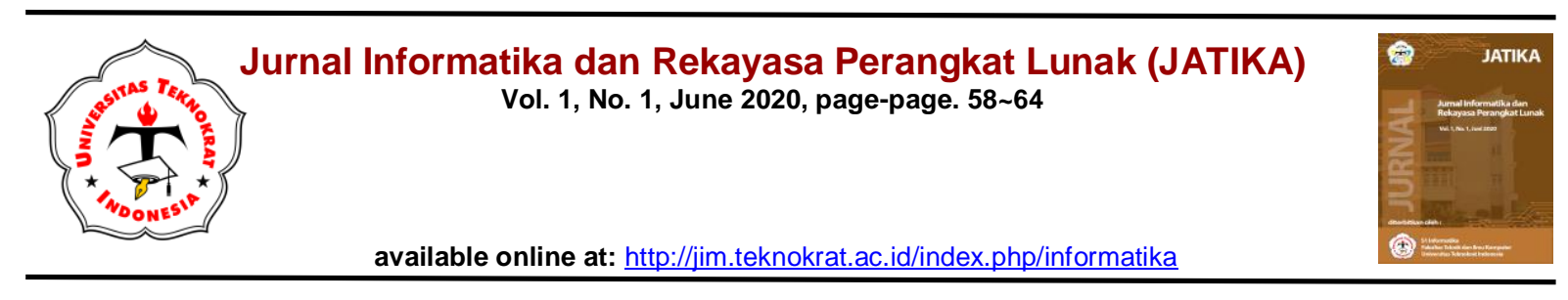

\title{
IMPLEMENTASI E-COMMERCE DENGAN CONTENT MANAGEMENT SYSTEM (CMS) OSCOMMERCE PADA SITUS PENJUALAN (Studi Kasus : Toko Cahaya Komputer)
}

\author{
Vanessa Ramadhanti ${ }^{1}$, Permata ${ }^{2}$ \\ S1 Informatika, Universitas Teknokrat Indonesia ${ }^{1,2}$
}

Email: vanessa.ramadhanti10@gmail.com¹,permata@teknokrat.ac.id ${ }^{2}$

\begin{tabular}{lll}
\hline Received: (Mei 2020) & Accepted: (Mei 2020) & Published: (Juni 2020)
\end{tabular}

\begin{abstract}
In line with the rapid development of technology, the use of the internet leads to changes in all activities in the present and the future. In general, cyberspace will turn into a tool for competition between one company and another. Business activities with the aim of taking profits such as sales, purchases, services, information, and trade through an intermediary that is through a computer network, making it easier for customers to be able to carry out buying and selling transactions without having to come into place. With ecommerce can make it easy for customers to find out what information products/services offered and facilitate customers in ordering products and services. Sources of information or data sources used through the method of direct interviews with speakers, make direct observations, and study literature in implementing E-Commerce. Describing the sales system, identifying problems, implementing E-Commerce in providing solutions to the problems faced is the goal in this study. This research provides a solution in the implementation of an E-Commerce system that is appropriate to be used to handle the problem of promotion and sales more effectively and efficiently by using OSCommerce applications based on open source. The results obtained after black box testing is $98 \%$ and web quality testing is $83 \%$ so that ECommerce implementation is feasible to use.
\end{abstract}

Keywords: E-Commerce, Implementation, Open Source, OSCommerce, Promotion.

\begin{abstract}
Abstrak
Sejalan dengan cepatnya perkembangan bidang teknologi, penggunaan internet yang menjurus kepada perubahan seluruh kegiatan di masa kini dan masa datang. Secara umum dunia maya akan berubah menjadi alat untuk persaingan antara perusahaan yang satu dengan yang lainnya. Kegiatan - kegiatan bisnis dengan tujuan mengambil keuntungan seperti penjualan, pembelian, pelayanan, informasi, dan perdagangan melalui perantara yaitu melalui suatu jaringan komputer, memudahkan costumer untuk dapat melakukan transaksi jual beli tanpa harus datang ke tempatnya. Dengan adanya e-commerce dapat memberikan kemudahan bagi pelanggan untuk mengetahui apa saja informasi produk-produk/jasa yang ditawarkan dan memudahkan pelanggan dalam memesan produk dan jasa. Sumber informasi atau sumber data yang digunakan melalui metode wawancara langsung dengan narasumber, melakukan observasi langsung, dan studi pustaka dalam implementasi E- Commerce. Mendiskripsikan sistem penjualan, mengidentifikasi permasalahan, melakukan implementasi $E$-Commerce dalam memberikan solusi atas permasalahan yang dihadapi merupakan tujuan dalam penelitian ini. Penelitian ini memberikan solusi dalam implementasi sistem E-Commerce yang layak digunakan menangani permasalahan promosi dan penjualan yang lebih efektif dan efisien dengan menggunakan aplikasi OSCommerce yang berbasis open source. Hasil yang diperoleh setelah dilakukan pengujian black box adalah 98\% dan pengujian web quality adalah 83\% sehingga implemetasi E-Commerce layak untuk digunakan.
\end{abstract}

Kata Kunci: E-Commerce, Implementasi, Open Source, OSCommerce, Promosi. 
To cite this article:

Vanessa Ramadhanti, Permata. (2020). IMPLEMENTASI E-COMMERCE DENGAN CONTENT MANAGEMENT SYSTEM (CMS)

OSCOMMERCE PADA SITUS PENJUALAN. Jurnal Informatika dan Rekayasa Perangkat Lunak, Vol(1), 58-64.

\section{PENDAHULUAN}

Electronic commerce (E-commerce) merupakan salah satu kemajuan teknologi yang terjadi sekarang ini terutama dalam dunia bisnis. Perusahaan di dalam perkembangan teknologi saat ini sangat memerlukan dukungan teknologi dalam proses bisnisnya agar mampu bersaing dan menjangkau semua pihak. Teknologi yang sedang berkembang dalam lingkungan bisnis salah satunya adalah E-commerce.Dalam implementasinya $E$ commerce terbagi menjadi 3 (tiga) yaitu Consumer to Consumer (C2C), Business to Consumer (B2C), dan Business to Business (B2B) (Sarwono, 2009). Pencapaian target bisnis dari suatu perusahaan dapat didasarkan pada pembagianE-commerce yang ada. Faktor utama dalam proses E-commerece adalah adanya interaksi penjual dan pembeli dengan penggunaan jaringan komputer secara on-lineyang bersifat electronic dalam transaksi bisnisyang diinginkan. Sejalan dengan cepatnya perkembangan bidang teknologi, penggunaan internet yang menjurus kepada perubahan seluruh kegiatan di masa kini dan masa datang. Secara umum cyber space akan berubah menjadi alat untuk persaingan antara perusahaan yang satu dengan yang lainnya. Penjualan adalah kegiatan-kegiatan bisnis dengan tujuan mengambil keuntungan seperti penjualan, pembelian, pelayanan, informasi, danperdagangan melalui perantara yaitu melalui suatu jaringan komputer, memudahkan costumer untuk dapatmelakukan transaksi jual beli tanpa harus datang ke tempatnya (Sulistiawati dan Sulistiani, 2018).

Sistem penjualan berbasis website akan mempermudah dalam pemasaran suatu produk dan jasa yang ditawarkan yang dapat diakses dimana saja dan kapan saja. Selain itu e-commerce juga dapat digunakan untuk bebagai transaksi dalam pemesanan suatu produk dan jasa. Dengan adanya e-commerce dapat memberikan kemudahan bagi pelanggan untuk mengetahui apa saja informasi produk-produk/jasa yang ditawarkan dan memudahkan pelanggan dalam memesan produk dan jasa tersebut (Juniansyah dkk, 2020). Banyak perusahaan telah memanfaat web sebagai media untuk lebih mempromosikan produk atau informasi tentang perusahaan mereka ke masyarakat umum. Tetapi tidak sedikit pula perusahaan yang masih belum memanfaatkan web khususnya perusahaan yang sedang berkembang seperti halnya Toko Cahaya Komputer. Toko Cahaya Komputerbergerak dalam penjualan dan pembelian komputer dan memiliki jenis-jenis produk komputer yang lengkap, sehingga dijadikan rujukanoleh masyarakat sekitar.Produk-produk yang tersedia meliputi dari laptop baru maupun bekasserta aksesoris perangkat lainnya. Namun dalam perekembangannya Toko Cahaya Komputer belum memaksimalkan dalam penggunaan teknologi informasidalam proses bisnisnya.

Proses bisnis yang belangsung masih dilakukan secara konvensionalbaik dalam proses mempromosikan produk dan transaksi penjualan serta pembelian antara pelanggan dengan toko yang di lakukan secara offline, sehingga dalam proses pembelian dan penjualanproduk yangditawarkan harus mendatangi toko secara langsung serta pencatatan transaksi yang masih manual, sehingga mengakibatkan informasi tentang produk yang di jual maupun informasi toko itu sendiri masih kurang efektif dan efisien.Oleh sebab itu, diperlukan perancangan dan implementasi E-commerceuntukmengatasi dalam mempromosikan produkdan penjualan produk baik komputer maupun aksesoris di Toko Cahaya Komputer agar dapat menjangkaukonsumen lebih luas.

\section{TELAAH PUSTAKA}

\section{Implementasi Sistem}

Implementasi sistem adalah peletakkan sistem pada suatu proses untuk dapat dioperasikantermasuk di dalamnya proses menuliskankode program untuk penerapan dalam suatu aplikasi tertentu. Adapun langkah langkah yang diperlukan dalam implementasi sistem adalah menerapkan rencana implementasi, melakukan kegiatan implementasi, dan tindak lanjut implementasi dari suatu sistem.

\section{Sistem Informasi}

Sistem informasi adalahsistem yang berjalandi dalam operasional suatu perusahaan atau organisasi dalam proses operasional, manajerial dan kegiatan strategi serta transaksi harian dari suatu perusahaan atau organisasi dan juga menyediakan laporan transaksi bisnis yang diperlukan.

\section{Website}

Website merupakan kumpulan darihalaman situs yang terdapat dalam sebuah domain atau subdomain, yang tempatnya berada didalam world wide web (www) di dalam koneksi jaringan. Websiteadalah himpunan situs web yang tersedia secara publik dan diakses dari sebuah URL yang menjadi "akar" (root), yang disebut beranda atau homepage. URL ini mengatur halaman web menjadi sebuah susunan, agar arus informasi 
berjalan sehingga dapat digunakan oleh penggunamelalui hyperlink-hyperlink yang ada dihalaman tersebut (Candra dan Dadang, 2013).

\section{Database}

Database merupakan himpunandata atau record yang saling berinteraksi dan berelasi satu dengan yang lain yang ditunjukan dengan adanya kunci dari tiap-tiap data yang ada. Pengolahan database merupakan prosespengelolaan terhadapdata-data yang berada di suatu perusahaan atau organisasi,yang mana dalam prosesnya data disusun, diurut, diambil sewaktu-waktu serta dapat ditampilkan dalam bentuk suatu laporan sehingga dapat memberikan informasi dari suatu transaksi yang terjadi dan databasedapat menunjukkan suatu himpunan data yang dipakai dalam suatu ruang lingkup perusahaan atau organisasi (Sovia dan Febio, 2011).

MySQL

MySQL merupakan salah satu jenis database yang digunakan. Awalnya mysql bekerja atau berjalan pada sistem operasi Unix dan Linux dalam perkembangannya banyak pengguna database yang menggunakan jenisdatabase ini, sehingga mysql meluncurkan versi yang dapat bekerja atau berjalan pada windows dan platform lainnya (Sovia dan Febio, 2011).

\section{E-Commerce}

Belanja melalui media internet sebagai pertukaran atau aktivitas yang dilakukan seorang konsumen melaluialat penghubung komputer sebagai dasarnya, dimanakomputer konsumen terhubung dengan internet danbisaberinteraksi dengan retailer atau toko maya yang menjualproduk dan atau jasa melalui jaringan. Belanja online dapat dilakukan dengan cara melakukan window shopping online pada web yang dituju (Megawaty dan Setiawan, 2017).

\section{Keuntungan E-Commerce}

Terdapat delapan keuntungan dalam melakukan perdagangan secara elektronik, yaitu:

1. Menurunkan biaya operasional (operational cost)

2. Meningkatkan pangsa pasar (market exposure).

3. Melebarkan jangkauan (global reach)

4. Meningkatkan loyalitas konsumen

5. Meningkatkan supplier management

6. Memperpendek waktu produksi.

7. Aliran pendapatan (Revenue stream) baru yang mungkin lebih menjanjikan dibandingkan sistem transaksi tradisional.

8. .Meningkatkan mata rantai pendapatan(value chain) (Candra dan Dadang, 2013).

\section{METODE PENELITIAN}

\section{A. Kerangka Penelitian}

Kerangka pemikiran dalam penelitian merupakan hubungan antara konsep-konsep yang ingin diamati atau diukur melalui penelitian yang akan dilakukan. Berdasarkan kerangka pemikiran yang ada, maka kerangka pemikiran yang digunakan dapat ditinjau pada gambar 1 di bawah ini. 


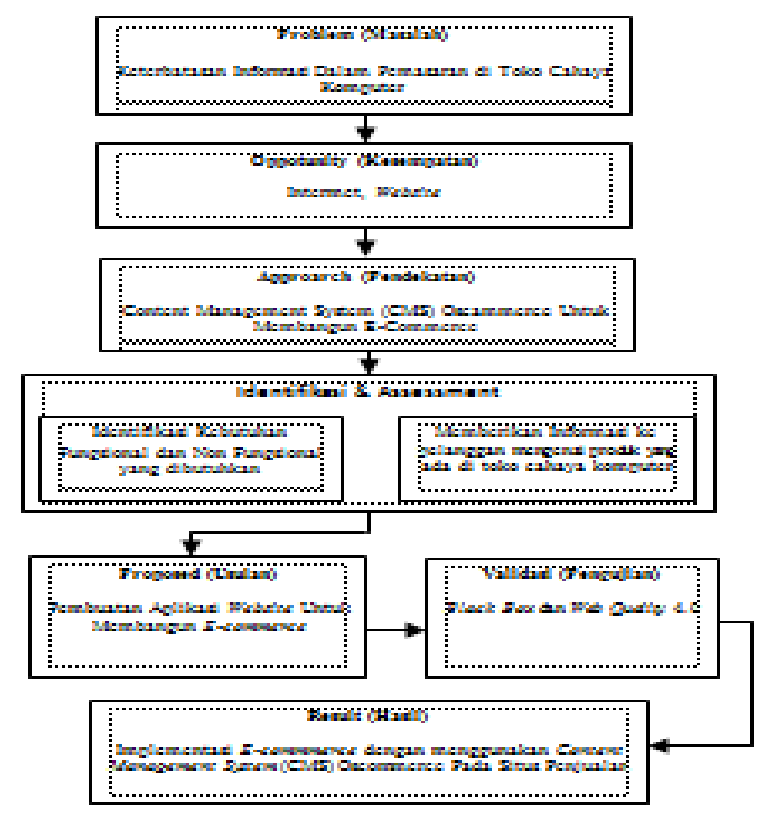

Gambar 1 Kerangka Penelitian

Keterangan:

\section{Problem (Masalah)}

Tahapan penelitian diawali dengan penentuan masalah penelitian. Pada penelitian ini masalah yang dihadapi adalah keterbatasan informasi dalam pemasaran produk yang ada di toko cahaya komputer, sehingga dari masalah tersebut dibutuhkan solusi yang mampu mengurangi permasalahan tersebut.

\section{Opportunity (Kesempatan)}

Kesempatan yang dimaksud adalah penelitian yang dilakukan peneliti sebelumnya. Penelitian ini memiliki acuan dalam melakukan penelitian yaitu "Perancangan Sistem Informasi Penyewaan Barang Elektronik pada CV. Nusantara Berbasis Online menggunakan CMS OSCommerce”,

\section{Approach (Pendekatan)}

Pendekatan dalam penelitian merupakan cara yang dilakukan penulis untuk menerapkan metode atau teknik yang diterapkan dalam suatu penelitian. Penelitian ini menggunakan metode pengenalan Content Management System (CMS), untuk perangkat yang digunakan dalam implementasi aplikasi website untuk menbangun $E$-commerce.

4. Identification\&Assasment (Identifikasi dan Tujuan)

Identifikasi berkaitan dengan variabel-variabel yang digunakan dalam penelitian ini, sehingga informasi yang disajikan sesuai dengan tujuan yang diharapkan.

\section{Proposed (Usulan)}

Usulan yang diajukan dalam penelitian ini adalah perancangan dan pembuatan aplikasi website sebagai media untuk membangun E-commerce.

\section{B. Use Case Diagram}

Use case diagram merupakan gambaran atau deskripsi darisebuah interaksi antara satu atau lebih aktor dengan sistem yang akan dibuat.Use case diagram digunakan untuk mengetahui fungsionalitasapa saja yang ada didalam suatusystem yang berjalan. Berikut adalah rancangan use casediagram pada aplikasi website Toko Cahaya Komputer. Use case dapatdilihat pada Gambar 2. 


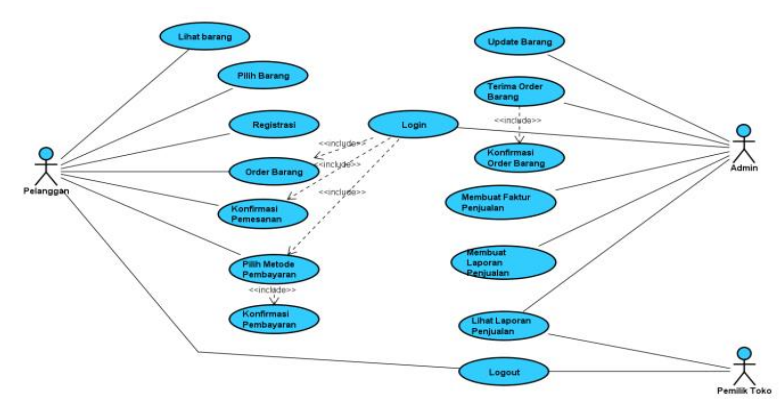

Gambar 2. Usecase Diagram

\section{HASIL DAN PEMBAHASAN}

\section{Pengujian}

Pengujian aplikasiakan dilakukan setelah penulisan kode program dikerjakan. Pengujian dilakukan untuk memeriksa dan memastikan bahwa komponen atau bagian dari aplikasi telah berfungsi sesuai denganyangdiharapkan. Pengujian perlu dilakukanuntuk mencarikelemahan atau kesalahan yang mungkin masih terjadi agar dapat diperbaiki.Pengujian dilakukan secara menyeluruh terhadap masing-masing aplikasi yang telah berjalan dengan benar dan baik.

\section{Pengujian Blackbox}

Pengujian blackboxmerupakan pengujian dari segi fungsionalitas suatuaplikasi tanpa melihat atau menguji desain dan kode program yang terdapat dalam suatu aplikasi. Tujuannya adalah untuk mengetahui fungsi-fungsi baik masukan dan keluaran dari suatu aplikasi sesuai dengan spesifikasi yang dibutuhkan dan berjalan dengan baik. Pengujian dilakukan dengan membuat kasus uji yang bersifat mencoba semua fungsi yang tersedia dari suatu apliaski dengan memakai perangkat lunak apakah telah sesuai dengan spesifikasi yang dibutuhkan.

Tabel 1 Hasil Pengujian Blackbox Dosen

\begin{tabular}{|c|c|c|c|}
\hline Kategori & Frekuensi Jawaban & Responden & Total Pertanyaan \\
\hline Diterima & 60 & 1 & 60 \\
\hline Ditolak & 1 & 1 & 59 \\
\hline
\end{tabular}

Rumus Perhitungan Pengujian

$=\frac{\text { jumlah pertanyaan diterima }}{\text { total pertanyaan }} \times 100 \%$

$=\frac{59}{60} \times 100 \%$

$=98,3 \%$ (Sangat Baik)

Tabel 2 Hasil Pengujian Blackbox Pemilik Toko

\begin{tabular}{|c|c|c|c|}
\hline Kategori & Frekuensi Jawaban & Responden & Total Pertanyaan \\
\hline Diterima & 8 & 1 & 8 \\
\hline Ditolak & 0 & 1 & 8 \\
\hline
\end{tabular}

Rumus Perhitungan Pengujian

$=\frac{\text { jumlah pertanyaan diterima }}{\text { total pertanyaan }} \times 100 \%=\frac{8}{8} \times 100 \%$

$=100 \%($ Sangat Baik $)$ 
Tabel 3 Hasil Pengujian Blackbox Admin

\begin{tabular}{|c|c|c|c|}
\hline Kategori & Frekuensi Jawaban & Responden & Total Pertanyaan \\
\hline Diterima & 29 & 3 & 29 \\
\hline Ditolak & 1 & 3 & 28 \\
\hline
\end{tabular}

$=\frac{\text { jumlah pertanyaan diterima }}{\text { total pertanyaan }} \times 100 \%$

$=\frac{28}{29} \times 100 \%$

$=96,5 \%$ (Sangat Baik)

Tabel 4 Hasil Pengujian Blackbox Pelanggan

\begin{tabular}{|c|c|c|c|}
\hline Kategori & Frekuensi Jawaban & Responden & Total Pertanyaan \\
\hline Diterima & 22 & 1 & 22 \\
\hline Ditolak & 0 & 1 & 22 \\
\hline
\end{tabular}

$=\frac{\text { jumlah pertanyaan diterima }}{\text { total pertanyaan }} \times 100 \%$

$=\frac{22}{22} \times 100 \%$

$=100 \%$ (Sangat Baik)

Setelah dilakukan perhitungan maka diperoleh sebuah hasil dari perhitungan dari beberapa responden. Dosen $98,3 \%$, pemilik toko mendapatkan hasil $100 \%$, admin mendapatkan hasil $96 \%$, pelanggan mendapatkan hasil $100 \%$. Maka diperoleh kesimpulan rata-rata hasil perhitungan dari beberapa responden yang telah melakukan pengujian mendapatkan hasil $98 \%$ yang hasilnya sangat layak untuk digunakan oleh toko cahaya komputer.

\section{Pengujian Webquality 4.0}

Merupakan hasil analisis pada WebQual 3.0 yang membawa pada identifikasi tiga dimensi dari kualitas website e-commerce, yaitu: kegunaan (usability), kualitas informasi (information quality) dan kualitas layanan interaksi (service interaction quality).

Tabel 5 Hasil pengujian web quality

\begin{tabular}{|l|c|}
\hline Kategori & Hasil \\
\hline Usability & $90 \%$ \\
\hline Information & $85 \%$ \\
\hline Service Interaction Quality & $76 \%$ \\
\hline Jumlah & $251 \%$ \\
\hline
\end{tabular}




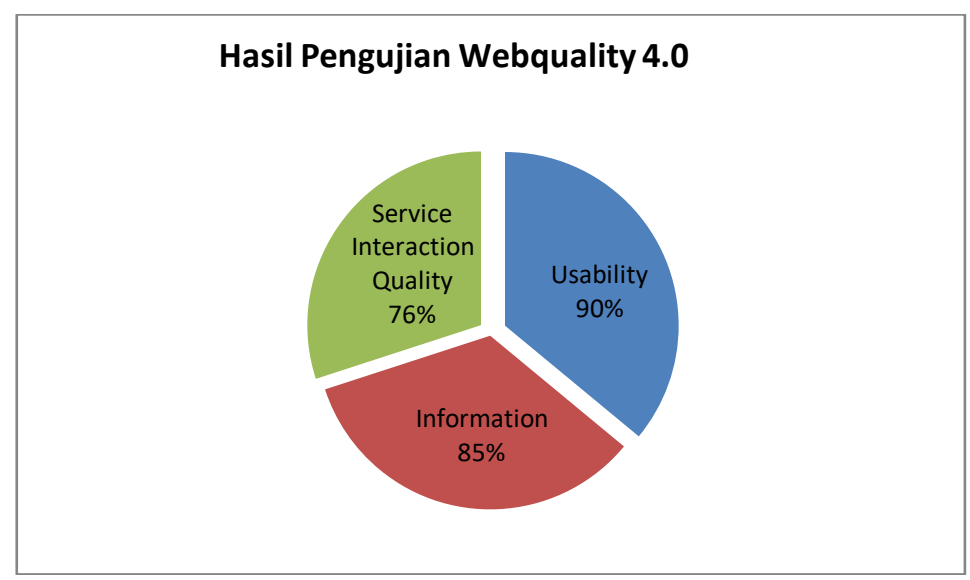

Gambar 7 Diagram Hasil Web Quality

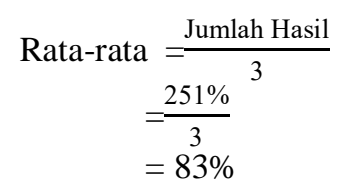

Setelah dilakukan perhitungan maka diperoleh sebuah hasil dari perhitungan beberapa responden. Usability mendapatkan hasil 90\%, Information mendapatkan hasil 85\%, Service Interaction Quality 76\%. Maka diperoleh kesimpulan rata-rata hasil perhitungan dari beberapa responden yang telah melakukan pengujian mendapatkan hasil $83 \%$ yang hasilnya layak untuk digunakan oleh Toko Cahaya Komputer.

\section{SIMPULAN}

Adapun kesimpulan yang diperoleh berdasarkan hasil dan pembahasan yang telah dijelaskan, yaitu :

1. Hasil perhitungan blackbox testingdari beberapa responden yaitu: respon ahli mendapatkan hasil $98,3 \%$, pemilik toko mendapatkan hasil $100 \%$, admin mendapatkan hasil $96 \%$, pelanggan mendapatkan hasil $100 \%$, maka diperoleh rata-rata hasil perhitungan mendapatkan hasil $98 \%$ yang hasilnyaaplikasi E-Commercesangat layak untuk digunakan.

2. Hasil perhitungan web quality mendapatkan hasil Usability mendapatkan hasil 90\%, Information mendapatkan hasil 85\%, Service Interaction Quality 76\%, maka diperoleh rata-rata hasil perhitungan mendapatkan hasil $83 \%$ yang hasilnya aplikasi E-Commercelayak untuk digunakan.

\section{DAFTAR PUSTAKA}

Al Fatta, H. 2007. Analisis dan Perancangan Sistem Informasi. Yogyakarta: Andi.

Barnes, S., dan Vidgen, R., (2003). Measuring Web Site Quality Improvements: A Case Study of the Forum on Strategic Management Knowledge Exchange. Industrial Management \& Data Systems, 103(5). pp: 297-309.

Candra dan Dadang, (2013). E-Business dan E-Commerce. Yogyakarta: Andi.

Hartono. (1989). Analisis dan Desain Sistem Infromasi. Yogyakarta: Andi.

Juniansyah, D, B; Susanto, R, E dan Wahyudi, D, A (2020). Pembuatan E-Commerce Pemesanan Jasa Event Organizer Untuk Zero Seven Entertaiment. Lampung: Jurnal Teknokompak. 14(1). pp: 41-46.

Megawaty, Ayu, D dan Setiawan, E (2017). Analisis Perbandingan Social Commerce Dari Sudut Pengguna Website. Lampung: Jurnal Teknoinfo. 11(1). pp: 10-13.

Rosa, A. S., Shalahudin, M. 2018. Rekayasa Perangkat Lunak (terstruktur dan berorientasi objek). Bandung: Informatika.

Sarwono. (2008). Teori E-Commerce. Yogyakarta: Gava Media.

Sovia, R, dan Febio, J. (2011). Membangun Aplikasi E-Library menggunakan HTML, PHP Script dan MySql Database. Padang: Jurnal Teknologi Informasi dan Pendidikan. 3(1). pp: 2086-4981.

Sulistiawati, dan Sulistiani, H(2018).Perancangan Dashboard Interaktif Penjualan (Studi Kasus : PT Jaya Bakery). Lampung: Jurnal Teknokompak. 12(1). pp: 15-17. 